\title{
Bone dysplasia, lethal Holmgren type
}

INSERM

\section{Source}

INSERM. (1999). Orphanet: an online rare disease and orphan drug data base. Bone dysplasia, lethal Holmgren type. ORPHA:1842

Bone dysplasia lethal Holmgren type (BDLH) is a lethal bone dysplasia characterized at birth by low birth weight, a rhizomelic dwarfism, bent femora and short chest producing asphyxia. It was described in three siblings from healthy, non-consanguineous parents of Finnish and in four siblings from non-consanguineous parents of French orig in with no family history of dwarfism. The initial cases could have been diagnosed as Desbuquois syndrome, or a recessive Larsen syndrome. There has been no further description of BDLH in the literature since 1988. 